\title{
Genetic relationship of Salmonella isolates found in subcutaneous abscesses in leopard geckos (Eublepharis macularius)
}

\author{
Magdalena Zając $^{1 凶}$, Aleksandra Maluta $^{2}$, Dariusz Wasyl ${ }^{1}$, \\ Magdalena Skarżyńska ${ }^{1}$, Anna Lalak ${ }^{1}$, Ilona Samcik ${ }^{1}$, \\ Renata Kwit ${ }^{1}$, Krzysztof Szulowski $^{1}$ \\ ${ }^{1}$ Department of Microbiology, National Veterinary Research Institute, 24-100 Puławy, Poland \\ ${ }^{2}$ Exotic Animals Hospital, 01-652 Warsaw, Poland \\ magdalena.zajac@piwet.pulawy.pl
}

Received: January 6, 2020 Accepted: August 24, 2020

\begin{abstract}
Introduction: The article describes the occurrence and phylogenetic relationship of Salmonella isolates found in subcutaneous abscesses of leopard geckos. The aim of the study was to determine the cause of the abscesses and to characterise isolated Salmonella strains. Material and Methods: Samples of abscesses from five animals and internal organs (lungs, liver, and gut) of three of them were tested for Salmonella according to the PN-EN ISO 6579:2002/A1:2007 standard. The antimicrobial resistance was evaluated by minimal inhibitory concentrations and the genetic similarity of the isolates was assessed with pulsed field gel electrophoresis (PFGE). Results: In total, seventeen Salmonella isolates belonging to five different serovars were found to be susceptible to all tested antimicrobials except streptomycin. The serovars were $S$. Hadar, $S$. Fluntern, $S$. Tennessee, S. enterica subsp. salamae 55:k:Z39, and $S$. Kentucky. Up to three serovars from different organs were isolated from the same individual. In two geckos, Salmonella were detected in the lungs. In three serovars, XbaI-PFGE typing revealed indistinguishable isolates from organs and abscesses. Conclusion: Multiple Salmonella serovars might be involved in abscess formation and infections. The occurrence of the same PFGE profiles of the isolates may testify to the role of opportunistic organisms in causing infection.
\end{abstract}

Keywords: leopard geckos, Salmonella, abscess, genetic relationship, pulsed field gel electrophoresis.

\section{Introduction}

One of the common dermatological problems seen in reptiles is cutaneous and subcutaneous abscesses containing an accumulation of caseous and thick pus, often seen as protuberances of skin. They can occur when pathogens are introduced into the tissue by a tumour or parasites or by trauma such as a bite wound or foreign body penetration. In some cases, abscesses are outward manifestations of serious internal problems and can be associated with underlying disease or stressrelated factors. Abscesses are often caused by opportunistic bacteria which can induce a disease under certain conditions and are found on and in the body of healthy reptiles. Few systematic studies have been attempted to describe and confirm the source of infection and causative agents of abscesses in reptiles. One of them can be Salmonella, which has been isolated from sick reptiles along with other bacteria (8). This bacterium is considered a natural component of the flora of the gastrointestinal tract in nearly $80 \%$ of reptiles $(16,17)$. Salmonella detected in those animals reveal a high diversity of subspecies and serovars, and several of the latter can cause infection in birds, mammals, and humans $(6,14,22)$. Relating to transmission to humans, this phenomenon is defined as reptile-associated salmonellosis (RAS) or reptileexotic-pet-associated salmonellosis (REPAS) and was noted in many European countries $(1,6,14)$.

\section{Material and Methods}

The material derived from five leopard gecko (Eublepharis macularius) females (gecko nos. 1-5) which were admitted to the Exotic Animals Hospital in 
Warsaw, Poland for clinical diagnosis. The animals had symptoms of disease such as decreased appetite, eye problems, and abscesses in the form of deformations of the head area, which appeared from one to two months before death (Fig. 1).

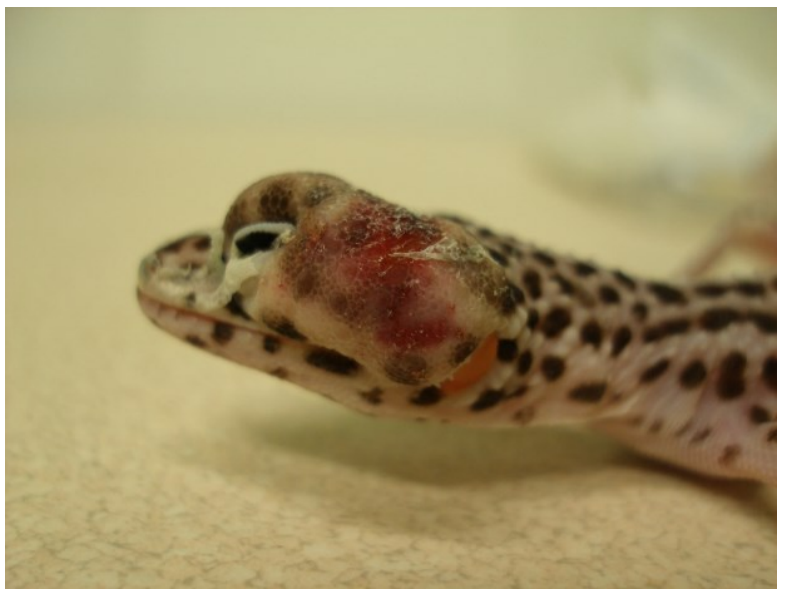

Fig. 1. Subcutaneous abscess on the head of a female leopard gecko

The animals derived from a basic breeding group consisting of 480 females and 170 males producing approximately 1,500 baby lizards in each breeding season. Reptiles were housed in a rack system in groups of four females and males kept separately except during the breeding season. The animals had unlimited access to feed (mealworm larvae), water, and powdered calcium, but no vitamin supplementation. Fifty females from two EU countries were introduced into the breeding group as new gene pool additions six months before the disease onset. By the end of the breeding season, 76 geckos, mainly females, had died with similar symptoms and a further 200 individuals were showing the first disease symptoms. The overall mortality reached nearly $15 \%$ of the breeding group.

As the first step in the research, abscesses from two live geckos were removed and tested. In the meantime three dead animals were delivered to the laboratory and samples of internal organs (lungs $(\mathrm{n}=3)$, liver $(\mathrm{n}=3)$, and gut $(\mathrm{n}=3))$, and abscesses $(\mathrm{n}=3)$ were investigated. All geckos derived from the same farm but had been housed in different cages. Samples were tested for the presence of Salmonella according to the PN-EN ISO 6579:2002/A1:2007 standard and identified according to WhiteKauffmann-Le Minor scheme using slide agglutination tests with commercial antisera (13). Resistance to ampicillin, cefotaxime, ceftazidime, ciprofloxacin, colistin, chloramphenicol, florfenicol, gentamycin, trimethoprim, kanamycin, nalidixic acid, streptomycin (Str), sulphamethoxazole, and tetracycline was tested with the minimal inhibitory concentration (MIC) determination method using EUMVS2 Sensititre plates (TREK Diagnostic Systems, USA). The MIC values were interpreted according to epidemiological cut-off values defined by EUCAST (10). The genetic similarity of the isolates was assessed with pulsed field gel electrophoresis (PFGE) carried out according to the PulseNet protocol following DNA digestion with $\mathrm{XbaI}$ and analysis with BioNumerics v.5.1 (Applied Maths, Belgium). The methods were described previously (23).

\section{Results}

Diseased animals were slightly to severely emaciated with skin remnants around eyes, toes, fingers, and tails and subcutaneous abscesses located on their heads, but without any clinical signs of salmonellosis. Blepharospasms and serious debris in conjunctival sacs were present. Oxyuridae eggs were common in faecal samples. Autopsy of three dead geckos showed enlarged yellowish livers, active ovaries with follicles, bloated intestines, enlarged adrenal glands, and substantial deformations of the skulls with caseous abscesses.

Table 1. Salmonella serovars found in tested geckos

\begin{tabular}{|c|c|c|}
\hline Gecko & $\begin{array}{l}\text { Isolation } \\
\text { source }\end{array}$ & $\begin{array}{l}\text { Salmonella } \\
\text { serovar }\end{array}$ \\
\hline No. 1 & abscess & S. Hadar, S. Fluntern \\
\hline No. 2 & abscess & $S$. Hadar, $S$. Fluntern \\
\hline No. 3 & $\begin{array}{l}\text { abscess } \\
\text { lungs } \\
\text { liver } \\
\text { gut }\end{array}$ & $\begin{array}{l}S . \text { Hadar } \\
S . \text { Hadar } \\
S . \text { Hadar } \\
S . \text { Kentucky, } S \text {. Fluntern }\end{array}$ \\
\hline No. 4 & $\begin{array}{l}\text { abscess } \\
\text { lungs } \\
\text { liver } \\
\text { gut }\end{array}$ & $\begin{array}{l}\text { S. Hadar } \\
\text { S. enterica } \text { subsp. salamae } 55: \mathrm{k}: \mathrm{z}_{39} \\
- \\
\text { S. Hadar, } S \text {. Fluntern }\end{array}$ \\
\hline No. 5 & $\begin{array}{l}\text { abscess } \\
\text { lungs } \\
\text { liver } \\
\text { gut }\end{array}$ & $\begin{array}{l}\text { S. Tennessee, } S \text {. enterica subsp. salamae } \\
55: \mathrm{k}: \mathrm{Z}_{39} \\
- \\
\text { S. enterica } \text { subsp. salamae } 55: \mathrm{k}: \mathrm{z}_{39} \\
\text { S. Tennessee }\end{array}$ \\
\hline
\end{tabular}

Salmonella was found in 12 out of 14 tested samples (Table 1). Seventeen isolates belonging to five Salmonella serovars were identified as $S$. Hadar, $S$. Fluntern, $S$. Tennessee, $S$. enterica subsp. salamae 55:k:z 39 , and $S$. Kentucky. $S$. Hadar $(\mathrm{n}=7)$ was dominant in abscesses and the internal organs of two geckos and $S$. Fluntern $(\mathrm{n}=4)$ was also common, being found mainly in abscesses and the gut. All tested abscesses were positive for Salmonella (Table 1). In each of three of them, two different Salmonella serovars were identified, and in different organs from the same gecko, up to three serovars were isolated. In two geckos, Salmonella was detected in lung samples. At least one of the Salmonella serovars from internal organs was also found in the abscesses. The isolates were susceptible to all tested antimicrobials except streptomycin. In three out of four serovars, XbaI-PFGE typing revealed isolates indistinguishable for their origin site (Fig. $2 \mathrm{a}-\mathrm{c}$ ). 


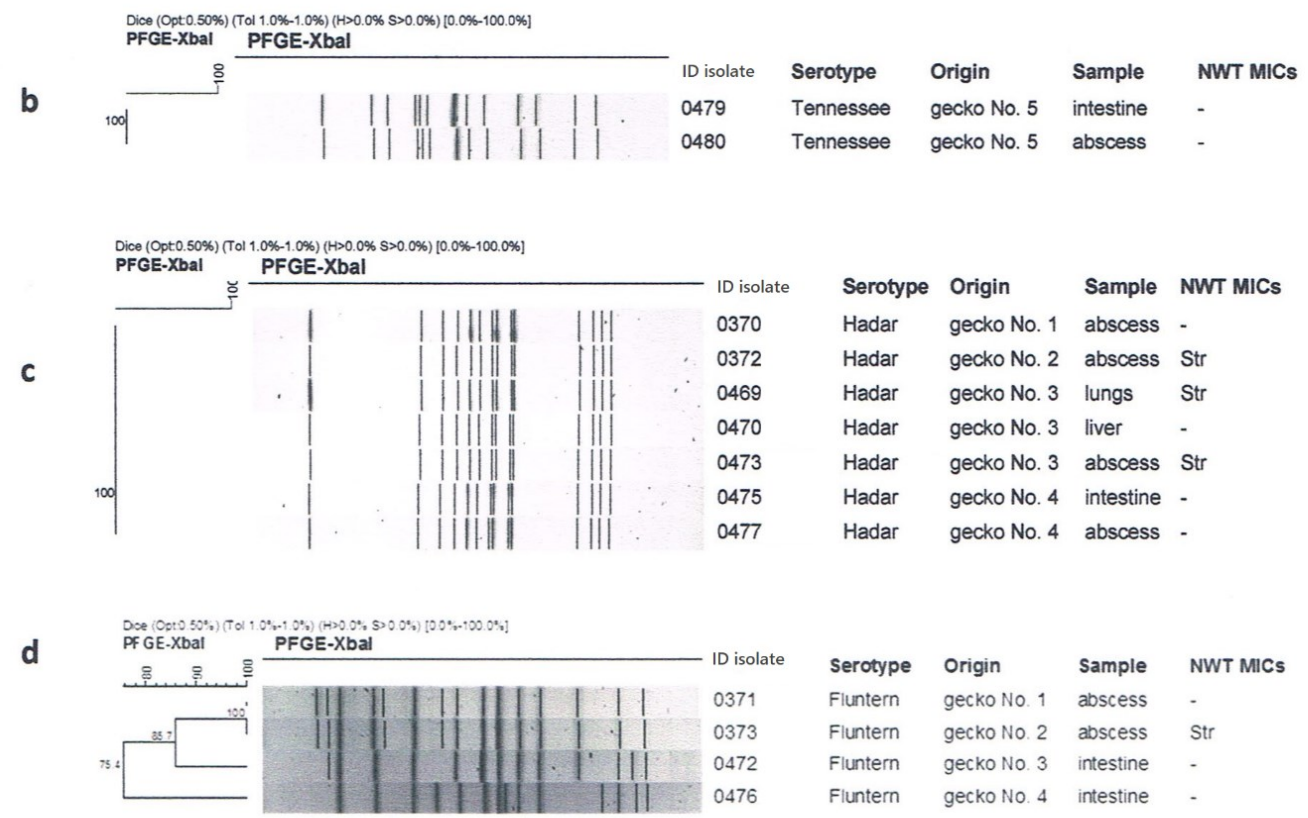

Fig. 2 a-d. Phylogenetic similarity of Salmonella serovars found in tested samples

$S$. Fluntern was the only serovar with different PFGE profiles found in abscesses and internal organs, which showed only $75 \%$ genetic relatedness, indicating independent infections with epidemiologically unrelated isolates (Fig. 2d). The fifth serovar was represented by a single isolate susceptible to tested antimicrobials and was $S$. Kentucky, which is well established in infections caused by RAS as clone ST314 (23).

\section{Discussion}

Reptiles have become popular companion animals in many countries. In Poland, it has led to their increased import and many small reptile farms arising throughout the country. A high demand for different reptile species is conducive to breeding of individuals of those species commercially.

To our knowledge, this is the first report describing the isolation of multiple Salmonella serovars from abscesses in leopard geckos. The infections in geckos might be considered common and they spread due to animal trade and exchange; this was noted from the anamnesis at the farm from which the studied geckos originated. The findings demonstrate that many Salmonella serovars found in reptiles can be involved in the formation of subcutaneous abscesses. Matching PFGE profiles were found associated with the isolates from organs and those from abscesses, and this may testify to the role of opportunistic organisms in the development of infection and support the assertion that abscesses are outward manifestations of broader health problems. The finding of Salmonella in gecko lungs seems to confirm subclinical disease and the compromised health status of the animals. A study on visceral distribution of Salmonella in healthy snakes found bacteria in all parts of the gastrointestinal tract but did not isolate it from the lungs or heart (7). Studies conducted on eastern box turtles showed no single bacterial agent responsible for aural abscesses, but Salmonella was not listed as a causative agent of them (15). In the current case, despite the fact that most abnormalities affected females, abscess formation did not seem to be related to sex but rather with vitamin A disorders. A similar observation was made in freeliving eastern box turtles (5). Deficiency of vitamin A and low humidity seems to be involved with abnormal shedding and ophthalmological problems (2, 12). Excessively intensive breeding, compromised animal welfare, poor hygiene and hypovitaminosis A could be primary reasons of abscess formation (3, 4, 19). Introduction of new animals could also contribute to the disruption of the microbiological balance on the breeding farm.

The study showed that many Salmonella serovars were involved in infection. Noteworthily, $S$. Hadar was the dominant serovar in the tested samples. This is considered one of the target serovars to detect in breeding flocks of Gallus gallus in the EU (11). In 
Poland, it is mainly isolated from poultry (18) but was in $6^{\text {th }}$ place in a list of the serovars which most frequently caused salmonellosis in humans in 2017 (9). The increasing popularity of reptiles as pets may lead to an increasing number of reptile-associated salmonellosis cases in humans. Some reports indicate $S$. Hadar and $S$. Tennessee isolated from reptiles as causes of salmonellosis in children $(20,21)$. Moreover, it should not be forgotten that every Salmonella serovar has zoonotic potential and salmonellosis could be a serious concern to address as a health hazard to reptile owners and breeders. All isolates were classified as wild type regarding all tested antimicrobials, except streptomycin. Knowledge of the presence of possible resistance mechanisms is important from the therapeutic and epidemiological point of view for the success of treating both animal salmonellosis and human RAS.

Summing up, proper care of animals is a prerequisite for successful breeding. The problems described, although not serious at the disease onset, lead to considerable losses and the closure of the breeding farm in short time. Not only different bacteria but also mixed flora including multiple Salmonella serovars might be involved in abscess formation and infections. Proper diagnosis of the pathogen is crucial for successful treatment of animals and prevention of breeders' economic losses. The occurrence of multiaetiological Salmonella infections on large breeding gecko farms must not be neglected because of its epidemiological and public health implications (23). The appropriate hygienic conditions should be recommended for the handling of reptiles.

Conflict of Interests Statement: The authors declare that there is no conflict of interests regarding the publication of this article.

Financial Disclosure Statement: The research was financed from the National Veterinary Research Institute's statutory sources.

Animal Rights Statement: None required.

\section{References}

1. Bertrand S., Rimhanen-Finne R., Weill F.-X., Rabsch W., Thornton L., Perevoscikovs J., van Pelt W., Heck M.: Salmonella infections associated with reptiles: the current situation in Europe. Euro Surveill 2008, 12, 13. doi: 10.2807/ese.13.24.18902-en.

2. Boyer T.H.: Hypovitaminosis A and hypervitaminosis A. In: Reptile medicine and surgery, edited by S. Divers and D. Mader, Saunders Elsevier, St. Louis, 2006, pp. 831-835.

3. Boyer T.H., Garner M.M., Reavill D.R., Steffes Z.J.: Common problems of leopard geckos (Eublepharis macularius). Proc Assoc Reptil Amphib Vet, 2013, 117-125.

4. Brown J.D., Richards J.M., Robertson J., Holladay S., Sleeman J.M.: Pathology of aural abscesses in free-living eastern box turtles (Terrapene carolina carolina). J Wildl Dis 2004, 40, 704-712.
5. Brown J.D., Sleeman J.M., Elvinger F.: Epidemiologic determinants of aural abscessation in free-living eastern box turtles (Terrapene carolina) in Virginia. J Wildl Dis 2003, 39, 918-921.

6. Centres for Disease Control: Multistate outbreak of human Salmonella Typhimurium infections associated with pet turtle exposure - United States, 2008. Morb Mortal Wkly Rep 2010, 59, 191-196.

7. Chiodini R.J.: Transovarian passage, visceral distribution, and pathogenicity of Salmonella in snakes. Infect Immun 1982, 36, $710-713$.

8. Cushing A., Pinborough M., Stanford M.: Review of bacterial and fungal culture and sensitivity results from reptilian samples submitted to a UK laboratory. Vet Rec 2011, 169, 390.

9. Czarkowski M., Cieleba E., Staszewska-Jakubik E., Kondej B.: Infectious diseases and poisonings in Poland in 2017. National Institute of Public Health - National Institute of Hygiene, Chief Sanitary Inspectorate - Department for Communicable Disease and Infection Prevention and Control, Warsaw, 2018, pp. $157-158$.

10. European Committee on Antimicrobial Susceptibility Testing EUCAST: MIC and zone distributions and ECOFFs. https://www.eucast.org/mic_distributions_and_ecoffs/.

11. European Parliament and the Council of the European Union: Regulation (EC) No 2160/2003 of the European Parliament and of the Council of 17 November 2003 on the control of Salmonella and other specified food-borne zoonotic agents. O J L $325,46,12 / 12 / 2003,1-15$.

12. Fitzgerald K.T., Vera R.: Dysecdysis. In: Reptile medicine and surgery, edited by S. Divers and D. Mader, Saunders Elsevier, St. Louis, 2006, pp. 778-786.

13. Grimont P.A.D., Weill F.-X.: Antigenic formulae of Salmonella serovars. WHO Collaborating Centre for Research on Salmonella, Institute Pasteur, Paris, 2007, 1-166.

14. Hoelzer K., Moreno Switt A.I., Wiedmann M.: Animal contact as a source of human non-typhoidal salmonellosis. Vet Res 2011, $42,1-27$.

15. Joyner P.H., Brown J.D., Holladay S., Sleeman J.M. Characterization of the bacterial microflora of the tympanic cavity of eastern box turtles with and without aural abscesses. J Wildl Dis 2006, 42, 859-864.

16. Pasmans F., De Herdt P., Chasseur-Libotte M.L., Ballasina D.L., Haesebrouck F.: Occurrence of Salmonella in tortoises in a rescue centre in Italy. Vet Rec 2000, 146, 256-258.

17. Pasmans F., Martel A., Boyen F., Vandekerchove D., Wybo I., Immerseel F.V., Heyndrickx M., Collard J.M., Ducatelle R., Haesebrouck F.: Characterization of Salmonella isolates from captive lizards. Vet Microbiol 2005, 110, 285-291.

18. Skarżyńska M., Hoszowski A., Zając M., Lalak A., Samcik I., Kwit R., Wasyl D.: Distribution of Salmonella serovars along the food chain in Poland, 2010-2015. J Vet Res 2017, 61, 173-179.

19. Sleeman J.M., Brown J., Steffen D., Jones D., Roberston J., Holladay S.: Relationships among aural abscesses, organochlorine compounds, and vitamin $\mathrm{A}$ in free-ranging eastern box turtles (Terrapene carolina carolina). J Wildl Dis 2008, 44, 922-929.

20. Weiss B., Rabsch W., Prager R., Tietze E., Koch J., Mutschmann F., Roggentin P., Frank C.: Babies and bearded dragons: sudden increase in reptile-associated Salmonella enterica serovar Tennessee infections, Germany 2008. Vector Borne Zoonotic Dis 2011, 11, 1299-1301.

21. Whitten T., Bender J.B., Smith K., Leano F., Scheftel J.: Reptileassociated salmonellosis in Minnesota, 1996-2011. Zoonoses Public Hlth 2015, 62, 199-208.

22. Zając M., Hoszowski A., Wasyl D., Szulowski K.: Salmonella in reptiles: epidemiology of infection and public health aspect. Med Weter 2011, 67, 376-379.

23. Zając M., Wasyl D., Hoszowski A., Le Hello S., Szulowski K.: Genetic lineages of Salmonella enterica serovar Kentucky spreading in pet reptiles. Vet Microbiol 2013, 166, 686-689. 